\title{
3D printing of beta-amyloid protein deposits along capillary walls
}

\author{
China Blue ${ }^{1,2}$, Seth S. Horowitz ${ }^{2}$, Peter J. Snyder*1,3,4 \\ ${ }^{1}$ Norman Prince Neurosciences Institute, Rhode Island Hospital, Providence, RI, USA \\ ${ }^{2}$ The Engine Institute, Warwick, RI, USA \\ ${ }^{3}$ Department of Neurology, Warren Alpert Medical School of Brown University, Providence, RI, USA \\ ${ }^{4}$ Rhode Island School of Design, Providence, RI, USA
}

Received: January 12, 2017

DOI: $10.5430 / j b g c . v 7 n 1 p 8$
Accepted: February 19, $2017 \quad$ Online Published: March 1, 2017

URL: https://doi.org/10.5430/jbgc.v7n1p8

\begin{abstract}
Abnormally high levels of neocortical beta-amyloid protein $(\mathrm{A} \beta+)$ reflect Alzheimer's disease $(\mathrm{AD})$ pathology in persons with clinical evidence of dementia or mild cognitive impairment (MCI). The abnormal aggregation of beta-amyloid protein in the brain neuropil may lead to either diffuse plaques and/or concentrated neuritic plaques, with the latter form of deposits often present in the vicinity of the cerebral microvasculature. The $\mathrm{A} \beta$ protein, with its crystalline molecular structure, infiltrates the vessel walls and compromises the blood-brain barrier (BBB). The physical basis for this was elegantly shown by Meyer and colleagues, in a 2008 publication showing two-dimensional (2D) confocal laser scanning microscopic imaging of vascular A $\beta$ protein deposits in APP23 transgenic mice. These investigators showed accumulations of "tuft-life structures", also referred to as "pompons" with protruding spikes on - and embedded within - microvessels. These pompons of beta-amyloid protein "consist of fibrillar structures, [and] can encircle and constrict capillaries, and are often associated with distortion of capillaries".

We were struck by both the heuristic value of the imaging of Meyer and colleagues, in explaining the root cause of both the amyloid-related alterations in the vascular bed, and depicting minute protein deposits that are both geometrically complex, seemingly delicate and fragile, and yet tenacious in their embedding within small vessel walls. We re-created these images with standard 3D printing technology (extruded plastic) for both educational/teaching and artistic purposes.
\end{abstract}

Key Words: Alzheimer's disease, Beta-amyloid, Amyloid, 3D printing, 3D modelling, Neurodegenerative, Cerebral amyloid angiopathy

\section{INTRODUCTION}

Alzheimer's disease (AD) is a complex neurodegenerative process with multiple etiologies and highly variable phenotypic presentations. ${ }^{[1]}$ Regardless, there is clear consensus in the field that abnormally high levels of neocortical beta-amyloid $(\mathrm{A} \beta+)$ indicate $\mathrm{AD}$ pathology in persons with clinical evidence of dementia or mild cognitive impairment
(MCI). ${ }^{[2-5]}$ With the advent of in vivo detection of levels of cerebral beta-amyloid $(\mathrm{A} \beta)$ using positron emission tomography (PET) scans, ${ }^{[6]}$ recent prospective studies have shown that, when followed prospectively, $\mathrm{A} \beta+$ cognitively healthy older adults show an increased rate of decline in cognitive function, particularly in the domain of episodic memory, when compared to $\mathrm{A} \beta$ - healthy older adults. ${ }^{[7-9]}$

\footnotetext{
${ }^{*}$ Correspondence: Peter J. Snyder, Ph.D.; Email: psnyder@lifespan.org; Address: Lifespan Hospital System, Suite 1.001, 1 Hoppin Street, Providence, RI 02903, USA.
} 
Early disease progression in AD may also directly lead to cardiovascular and cerebrovascular changes ${ }^{[10,11]}$ and these diseases share multiple risk factors and pathophysiologic mechanisms. ${ }^{[11]}$ Clinical studies demonstrate that even mild cerebrovascular pathology results in reduced cognitive performance in very early AD. ${ }^{[12,13]}$ Additionally, there is evidence that vascular/cerebrovascular pathology can accelerate the progression of preclinical AD. ${ }^{[14,15]}$

The abnormal aggregation of beta-amyloid protein in the brain neuropil may lead to either diffuse plaques and/or concentrated neuritic plaques, with the latter form of deposits often present in the vicinity of the cerebral microvasculature. The $\mathrm{A} \beta$ protein, with its crystalline molecular structure, infiltrates the vessel walls and compromises the blood-brain barrier (BBB). ${ }^{[16]}$ Deposition of $\mathrm{A} \beta$ protein within the walls of cerebral blood vessels also leads to CAA, increasing the risk of cerebral haemorrhage. ${ }^{[17,18]}$ In an APP/PS1 transgenic mice study with induced hyperhomocysteinemia, Sudduth and colleagues showed that congophilic amyloid deposition was decreased within the parenchyma, but was significantly increased in the vasculature in CAA. This suggests that cerebrovascular disease (CBVD) can significantly impact $\mathrm{A} \beta$ distribution in the brain by vascular deposition, and that such deposition can induce micro-haemorrhages and activate neuroinflammation. ${ }^{[19]}$ In an in vivo study of Sprague-Dawley rats, infusion of solubilized $\mathrm{A} \beta$ peptides enhanced constriction of cortical and peripheral vessels, contributing to cerebral hypoperfusion and leading to decreased blood flow and increased vascular resistance. ${ }^{[20]}$ The risk of both repeated haemorrhagic strokes, as well as ischemic events due to vessel wall stenosis and oligaemia, increases with continued $\mathrm{A} \beta$ accumulation for both CAA and AD patients. This pathologic cascade leads to medial temporal atrophy, cognitive decline and progressive brain atrophy. ${ }^{[17]}$ Finally, vascular $\mathrm{A} \beta$ deposits have been shown in vitro to induce degeneration of human and murine cerebrovascular smooth muscle and endothelial cells, resulting in vasoconstriction, intraluminal thickening, inhibiting angiogenesis, impairing vascular tone and decreasing total cerebral blood flow. ${ }^{[21]}$

Because the $\mathrm{A} \beta$ protein tends to accumulate alongside, and to embed within, cerebrovascular walls, there is also an added risk to the integrity of those same vessel walls when novel therapeutics work by removing $\mathrm{A} \beta$ plaques from the cerebral parenchyma. ${ }^{[22]}$ Specifically, several immunotherapies that target cerebral $\mathrm{A} \beta$ burden have been placed into clinical trials in recent years, and one of the more important serious adverse events associated with these interventions has been the incidence of "amyloid-related imaging abnormalities" (ARIA) on structural MRI imaging. Two forms of ARIA have been described; abnormalities leading to parenchymal edema or sulcal effusions, and abnormalities leading to hemosiderin deposition. The former appears to be slightly more common, but there is high overlap suggestive of a common pathophysiologic mechanism. ${ }^{[22]}$ Put simply, the removal of $\mathrm{A} \beta$ protein from vessel walls may lead to risk of vasogenic edema and micro-haemorrhages. ${ }^{[23,24]}$

Given the propensity of $\mathrm{A} \beta$ protein deposits to either lead to stenosis and reduced blood flow (one might assume that the smallest and most delicate of microvascular beds are also most susceptible to such insults), or to vasogenic edema and micro-haemorrhages when physically removed from vessel walls, it is important to understand the basis for these diseaserelated vascular changes, and risk of serious adverse events with amyloid-reducing therapeutics. The physical basis for this was elegantly shown by Meyer and colleagues, in a 2008 publication showing absolutely gorgeous two-dimensional (2D) confocal laser scanning microscopic imaging (relying on a difficult and labour-intensive corrosion casting technique) of vascular $\mathrm{A} \beta$ protein deposits in APP 23 transgenic mice. ${ }^{[25]}$ These investigators showed accumulations of "tuftlife structures", also referred to as "pompons" with protruding spikes on - and embedded within - microvessels. These pompons of beta-amyloid protein "consist of fibrillar structures, [and] can encircle and constrict capillaries, and are often associated with distortion of capillaries". ${ }^{[25]}$

We were struck by both the heuristic value of the imaging of Meyer and colleagues, ${ }^{[25]}$ in explaining the root cause of both the amyloid-related alterations in the vascular bed, as well as the risk of ARIA with removal of the protein from vessel walls, as well as the sheer beauty of these images - depicting minute protein deposits that are both geometrically complex, seemingly delicate and fragile, and yet tenacious in their embedding within small vessel walls. We were moved to recreate these images ${ }^{[25]}$ in $3 \mathrm{D}$, for both educational/teaching and artistic purposes.

\section{METHOD}

A 2D confocal laser scanning microscopic image of betaamyloid "pompons", embedded in microvessels, ${ }^{[25]}$ was used as a basis for generating the three-dimensional (3D) model. The image was imported into a 3D NURBs based CAD program (Rhino 3D, v 5.0, McNeel \& Associates, Seattle, WA, USA) and then converted into a 3D mesh to provide spatial reference for reconstruction of 3D structures. Microvessels were reconstructed by building tubes of variable diameter around derived centerlines with their surface texture extrapolated from the image and applied as a mesh surface using the ApplyMeshUVN command. Amyloid protein "pompom" structures were created by analysing diameter and distribution of protrusions and recreating the structures using a 3D 
polar array of spines matching the protein structures. These spines were then joined together to make a single structure using a mesh Boolean Union command. Three versions of these assembled structures were created (two microvessels with amyloid pompoms, and one microvessel without and embedded amyloid protein) were then manipulated into proper position and assembled from these basic elements using mesh Boolean operations based on the source image. Final assemblages were then exported as stereolithography (.stl) files to prepare for 3D printing.

Stereolithography files were oriented, sliced and saved as gcodes using Simplify 3D (v 2.2.2, Simplify 3D LLC, Blue Ash, OH, USA) and printed on a Wanhao Duplicator 4S FDM printer (Wanhao USA, Miami, FL, USA), using default medium resolution settings using natural colored acrylonitrile butadiene styrene (ABS) $1.75 \mathrm{~mm}$ filament (IC3D LLC, Columbus, Ohio, USA).

\section{Results \\ Completed 3D prints}

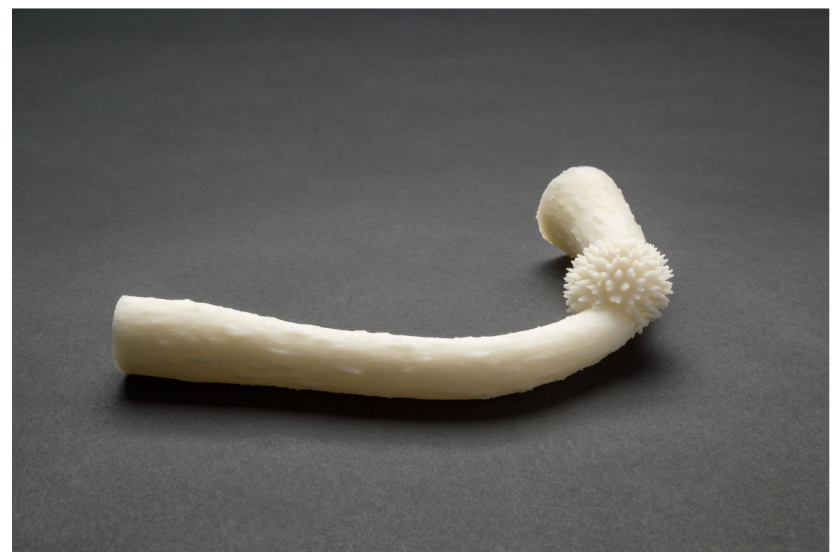

Figure 1. Plastic filament 3D print, with design based on a groundbreaking vascular casting and scanning electron microscopy study of Meyer et al. (2008). ${ }^{[25]}$ Beta-amyloid protein forming "pompom-like" clumps attached to brain microvessels of APP23 transgenic mice, an animal model of Alzheimer's disease (AD). This toxic form of amyloid protein is characteristic of $\mathrm{AD}$, and is believed to cause early damage to the microvasculature. (photo credit: Aaron Usher III)

\section{Discussion}

Three-dimensional printing of beta-amyloid protein physically embedded within the walls of microvessels (as imaged in the APP23 transgenic mouse model $)^{[25]}$ allows for a visual understanding of the relationship between AD and related cerebrovascular risk in a highly intuitive and visceral manner. The models we have generated (see Figures 1 and 2) have already been used very effectively by one of us (P.J.S.) for physician, patient and student education. We also plan to use the larger assembly of these models (see Figure 2) in an upcoming planned art exhibit in Rhode Island. Hence, these models serve a dual role as both realistic teaching tools as well as a visually-compelling statement of how the disease process degrades such fine, vulnerable vascular structures.

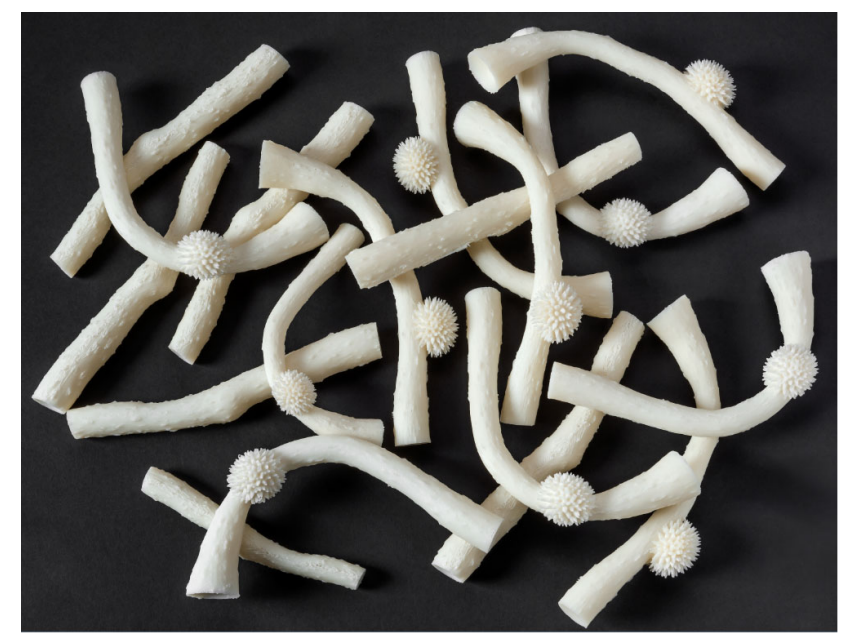

Figure 2. Grouping of three different variations of the model shown in Figure 1, to convey a sense of what a plexus of such microvessels look like in situ (photo credit: Aaron Usher III)

Three-dimensional modelling has been a central tool for medical pedagogy for centuries, ranging from the incredibly detailed 18th century wax anatomical figures by Clemente Susini ${ }^{[26]}$ to the most current structural model of Dengue NS5 RNA-dependent RNA polymerase hosted on the NIH 3D Print Exchange. ${ }^{[27]}$ And while 3D printing has been in existence since the mid-1980s, it is only in the last decade or so that both hardware and software improvements have made this practical for use by non-specialists to actualize digital datasets in physical form. Within just the past few years, 3D modelling and printing has evolved from a specialized engineering process to one that has the potential to transform education, research, art and applied clinical practices in disciplines ranging from paleontology, ${ }^{[28]}$ to planetary geology, ${ }^{[29]}$ and from biomaterial engineering ${ }^{[30]}$ to pharmaceutical manufacturing. ${ }^{[31]}$

The greatest strength of 3D printing lies in its ability to allow individuals to physically manipulate and explore natural and artificial phenomena normally out of human perceptual reach using our innate visuo-haptic sensory modalities. At the macro scale, 3D modelling and printing have been used to improve surgical teaching of hepatic segmentation, ${ }^{[32]}$ to allow creation of inexpensive, anatomically correct temporal 
bone models for dissection and surgical practice, ${ }^{[33]}$ and have even been the basis for 4D simulation to help with surgical planning, for example, using scans in different positions to create 3D printed models of thumb bones in abduction, opposition and key pinch positions. ${ }^{[34]}$ At the other end of the scale, this technology not only makes nano- and microscale structures visible and manipulable without imaging software, but it is becoming a critical technology for establishment of microscale cellular organization for research and clinically useful engineered tissues. ${ }^{[35,36]}$ In addition to our own use of this same technology to construct models of amyloid aggregation along microvessel walls, taken from 2D confocal laser scanning microscopic imaging, we are now exploring the utility of 3D printing of retinal microvasculature, taken from optical coherence tomographic imaging, to aid in our search for identifiable retinal biomarkers of disease burden, as well as heuristic devices of the teaching of disease-related pathophysiology.

\section{CONFLiCTS OF INTEREST Disclosure}

C.B. \& P.J.S. contributed equally to the design of the 3D model, and both C.B. \& S.S.H. were responsible for the fine-tuning of the model and producing the 3D prints. Both S.S.H. \& P.J.S. collaborated on the preparation of this report. None or the authors have any relevant conflicts to disclose. China Blue serves as Artist-in-Residence for the Norman Prince Neurosciences Institute, at the Rhode Island Hospital, Providence, RI, U.S.A.

\section{REFERENCES}

[1] Au R, Piers RJ, Lancashire L. Back to the future: Alzheimer's disease heterogeneity revisited. Alzheimer's \& Dementia: Diagnosis, Assessment \& Disease Monitoring. 2015; 1: 368-370. https: //doi.org/10.1016/j.dadm.2015.05.006

[2] McKhann GM, Knopman DS, Chertkow H, et al. The diagnosis of dementia due to Alzheimer's disease: Recommendations from the National Institute of Aging and the Alzheimer's Association workgroup. Alzheimer's \& Dementia. 2011; 7: 263-269. PMid: 21514250. https://doi.org/10.1016/j.jalz.2011.03.005

[3] Villemagne VL, Burnham S, Bourgeat $\mathrm{P}$, et al. Amyloid $\beta$ deposition, neurodegeneration and cognitive decline in sporadic Alzheimer's disease: A prospective cohort study. Lancet Neurology. 2013; 12: 357367. https://doi.org/10.1016/S1474-4422(13)70044-9

[4] Uchida K, Shan L, Suzuki H, et al. Amyloid- $\beta$ sequester proteins as blood-based biomarkers of cognitive decline. Alzheimer's \& Dementia: Diagnosis, Assessment \& Disease Monitoring. 2015; 1: 270-280. https://doi.org/10.1016/j.dadm.2015.04.003

[5] Ashton NJ, Kiddle SJ, Graf J, et al. Blood protein predictors of brain amyloid for enrichment in clinical trials? Alzheimer's \& Dementia: Diagnosis, Assessment \& Disease Monitoring. 2015; 1: 48-60. PMid: 27239491. https://doi.org/10.1016/j.dadm.2014.11.005

[6] Yeo JM, Waddell B, Khan Z, et al. A systematic review and metaanalysis of 18 F-labeled amyloid imaging in Alzheimer's disease. Alzheimer's \& Dementia: Diagnosis, Assessment \& Disease Monitoring. 2015; 1: 5-13. PMid: 27239488. https://doi.org/10.1 016/j.dadm.2014.11.004

[7] Doraiswamy PM, Sperling RA, Johnson K, et al. Florbetapir F 18 amyloid PET and 36-month cognitive decline: A prospective multicenter study. Molecular Psychiatry. 2014; 19: 1044-1051. PMid: 24614494. https://doi.org/10.1038/mp.2014.9

[8] Mormino EC, Betensky RA, Hedden T, et al. Amyloid and APOE E4 interact to influence short-term decline in preclinical Alzheimer's disease. Neurology. 2014; 82: 1760-1767. PMid: 24748674. https: //doi.org/10.1212/WNL.0000000000000431

[9] Small GW, Siddarth P, Kepe V, et al. Prediction of cognitive decline by positron emission tomography of brain amyloid and tau. Archives of Neurology. 2012; 69: 215-222. PMid: 22332188. https://doi.org/10.1001/archneurol.2011.559
[10] Santos CY, Lim YY, Wu WC, et al. Resting-State Cardiac Workload is Related to Both Increased Neocortical Aggregation of $\beta$-Amyloid and Relative Impairments in Spatial Working Memory in Pre-Clinical Alzheimer's Disease. Journal of Alzheimer's Disease. 2016; 50(1): 127-131. PMid: 26639961. https://doi.org/10.3233/JAD-1 50576

[11] Santos CY, Snyder PJ, Wu WC, et al. Pathophysiologic relationship between Alzheimer's disease, cerebrovascular disease and cardiovascular risk: A review and synthesis. Alzheimer's \& Dementia: Diagnosis, Assessment \& Disease Monitoring 2017; in press. https://doi.org/10.1016/j.dadm.2017.01.005

[12] Snowdon DA, Greiner LH, Mortimer JA, et al. Brain infarction and clinical expression of Alzheimer's disease. The Nun Study. JAMA. 1997; 277: 813-817. PMid: 9052711. https://doi .org/10.100 1/jama.1997.03540340047031

[13] Esiri MM, Nagy Z, Smith MZ, et al. Cerebrovascular disease and threshold for dementia in the early stages of Alzheimer's disease. Lancet. 1999; 354: 919-920. https://doi.org/10.1016/S014 0-6736 (99) 02355-7

[14] Helzner EP, Luchsinger JA, Scarmeas N, et al. Contri-bution of vascular risk factors to the progression in Alzheimer disease. Arch Neurol. 2009; 66: 343-348. PMid: 19273753. https://doi.org/10.100 1/archneur.66.3.343

[15] Silvestrini M, Pasqualetti P, Baruffaldi R, et al. Cerebrovascular reactivity and cognitive decline in patients with Alzheimer disease. Stroke. 2006; 37: 1010-1015. PMid: 16497984. https: //doi.org/10.1161/01.STR.0000206439.62025.97

[16] Kalaria RN. Cerebral vessels in ageing and Alzheimer's disease. Pharmacol. Ther. 1996; 72: 193-214. https://doi.org/10.1016/s0 163-7258 (96) 00116-7

[17] Kalaria RN, Akinyemi R, Ihara M. Does vascular pathology contribute to Alzheimer changes? Journal of the Neurological Sciences. 2012; 322: 141-147. PMid: 22884479. https://doi.org/10.101 $6 / j \cdot j n s .2012 .07 .032$

[18] Keable A, Fenna K, Yuen H M, et al. Deposition of amyloid $\beta$ in the walls of human leptomeningeal arteries in relation to perivascular drainage pathways in cerebral amyloid angiopathy. Biochimica et Biophysica Acta (BBA) - Molecular Basis of Disease. 2015; in press.

[19] Sudduth TL, Weekman EM, Brothers HM, et al. $\beta$-amyloid deposition is shifted to the vasculature and memory impairment is exac- 
erbated when hyperhomocysteinemia is induced in APP/PS1 transgenic mice. Alzheimers Res Ther. 2014; 6: 32. PMid: 24991237. https://doi.org/10.1186/alzrt262

[20] Suo Z, Humphrey J, Kundtz A, et al. Soluble Alzheimers $\beta$-amyloid constricts the cerebral vasculature in vivo. Neuroscience Letters 1998; 257: 77-80. https://doi.org/10.1016/S0304-3940(98 ) 00814-3

[21] Miao J, Xu F, Davis J, et al. Cerebral microvascular amyloid $\beta$ protein deposition induces vascular degeneration and neuroinflammation in transgenic mice expressing human vasculotropic mutant amyloid $\beta$ precursor protein. Am J Pathol. 2005; 167: 505-515. https://doi.org/10.1016/S0002-9440(10)62993-8

[22] Barakos J, Sperling R, Salloway S, et al. MR imaging features of amyloid-related imaging abnormalities. Am J Neuroradiol. 2013; 34(10): 1958-65. https://doi.org/10.3174/ajnr.A3500

[23] Sperling R, Salloway S, Brooks DJ, et al. Amyloid-related imaging abnormalities in patients with Alzheimer's disease treated with bapineuzumab: a retrospective analysis. Lancet Neurol. 2012; 11(3): 241-9. https://doi.org/10.1016/S1474-4422(12) 70015-7

[24] Salloway S, Sperling R, Fox NC, et al. Bapineuzumab 301 and 302 Clinical Trial Investigators. Two phase 3 trials of bapineuzumab in mild-to-moderate Alzheimer's disease. N Engl J Med. 2014; 370(4): 322-33. https://doi.org/10.1056/NEJMoa1304839

[25] Meyer EP1, Ulmann-Schuler A, Staufenbiel M, et al. Altered morphology and 3D architecture of brain vasculature in a mouse model for Alzheimer's disease. Proc Natl Acad Sci USA. 2008; 105(9): 3587-92. https://doi.org/10.1073/pnas. 0709788105

[26] Josephinum: Collections of the Medical University of Vienna. Vienna: Austria. [cited 2017 Jan 10]. Available from: www . josephin um.ac.at/

[27] NIH 3D Print Exchange. U.S. Department of Health and Human Services - National Institutes of Health. Bethesda: Maryland. [cited 2017 Jan 10]. Available from: http://3dprint.nih.gov/disc over/3dpx-003110
[28] Knecht B, Garwood R, Hegna T. First CT-scan reconstruction of Graephonus, a late Carboniferous whip spider (Arachnida: Amblypygi) from c Coseley, Staffordshire, UK. Geological Society of America (Abstract). 2012; 44: 90.

[29] Horowitz SS, Schultz PH. Printing space: Using 3D printing of digital terrain models in geosciences education and research. J. Geosci. Edu. 2014; 62: 138-145. https://doi.org/10.5408/13-031.1

[30] Leukers B, Ulkan HG, Irsen SH, et al. Hydroxyapatite scaffolds for bone tissue engineering made by 3D printing. J. Mat. Sci: Mat. In Med. 2005; 16: 1121-1124. PMid: 16362210. https: //doi.org/10.1007/s10856-005-4716-5

[31] orman J, Mudarawe RD, Moore CM, et al. A new chapter in pharmaceutical manufacturing: 3D-printed drug products. Adv Drug Deliv Rev. 2016; https ://doi.org/10.1016/j . addr.2016.03.001

[32] Kong X, Nie L, Zhang H, et al. Do three-dimensional visualization and three-dimensional printing improve hepatic segment anatomy teaching? A randomized controlled study. J Surg Educ. 2016; 73 : 264-269. PMid: 26868314. https://doi.org/10.1016/j.jsur g. 2015.10.002

[33] Mowry SE, Jammal H, Myer C, et al. A novel temporal bone simulation model using 3D printing techniques. Otol Neurotol. 2015; 36: 1562-1565. PMid: 26375979. https://doi.org/10.1097/MAO. 0000000000000848

[34] Chae MP, Hunter-Smith DJ, De-Silva I, et al. Four-dimensional (4D) printing: A new evolution in computed tomography-guided stereolithographic modeling. Principles and application. J Reconstr Microsurg. 2015 Jul; 31(6): 458-63. PMid: 25868154. https : //doi.org/10.1055/s-0035-1549006

[35] Bagley JR, Galpoin AJ. Three-dimensional printing of human skeletal muscle cells: An interdisciplinary approach for studying biological systems. Biochem Mol Biol Educ. 2015; 43(6): 403-7. PMid: 26345697. https://doi.org/10.1002/bmb. 20891

[36] Johnson BN, Lancaster KZ, Zhen G, et al. 3D printed anatomical nerve regeneration pathways. Adv Funct Mater. 2015; 25: 62056217. PMid: 26924958. https://doi.org/10.1002/adfm. 201 501760 